\title{
Indications and Results of Repair of the Rhumatismal Valve in Children in Senegal concerning 63 Cases
}

\author{
Momar Sokhna Diop*, Papa Amath Diagne, Ndeye Fatou Sow, Papa Salmane Ba, Magaye Gaye, \\ Pape Ousmane Ba, Souleymane Diatta, Moussa Seck Diop, Mareme Soda Mbaye, \\ Pape Adama Dieng, Amadou Gabriel Ciss, Assane Ndiaye
}

Thoracic and Cardiovascular Surgery Center, Cheikh Anta Diop University, Dakar, Sénégal

Email: *momarsokhna08@yahoo.fr, diagnepapaamathdiagne@gmail.com, zenefes@gmail.com, mansalb@yahoo.fr, mgaye99@yahoo.fr, papy.ba@gmail.com,soul.diatta@yahoo.fr, sirmsd9@gmail.com, sodaabeck24@yahoo.fr, padiengsala@yahoo.fr, cissgaby@yahoo.fr, lazanat@yahoo.fr, mondiaye@orange.sn

How to cite this paper: Diop, M.S., Diagne, P.A., Sow, N.F., Ba, P.S., Gaye, M., Ba, P.O., Diatta, S., Diop, M.S., Mbaye, M.S., Dieng, P.A., Ciss, A.G. and Ndiaye, A. (2020) Indications and Results of Repair of the Rhumatismal Valve in Children in Senegal concerning 63 Cases. World Journal of Cardiovascular Surgery, 10, 51-58. https://doi.org/10.4236/wjcs.2020.105007

Received: April 6, 2020

Accepted: May 9, 2020

Published: May 12, 2020

Copyright $\odot 2020$ by author(s) and Scientific Research Publishing Inc. This work is licensed under the Creative Commons Attribution International License (CC BY 4.0).

http://creativecommons.org/licenses/by/4.0/

\section{(c) (i) Open Access}

\begin{abstract}
In Africa, acute rheumatic fever is endemic. Cardiac involvement is one of the most common complications in the form of valvular heart disease representing all damages to the heart valves. It is in this perspective that we realized this study whose general objective was to evaluate the results of mitral repair surgery in children in Senegal and the specific objective was to state the indications for mitral repair surgery and assess the results in terms of morbidity and mortality. This is a retrospective and analytical monocentric study, in the thoracic and cardiovascular surgery department of FANN National University Hospital Center in Dakar. It took place over a period of 30 months. All the patients who underwent mitral surgery, aged less than 18 years were included. The total number of patients was 63 , including 39 girls and 24 boys, a sex ratio of 0.62 . The average age at the time of the surgery was 12 years old [5 17]. The functional symptomatology was dominated by the dyspnea found in all the patients. Cardiac ultrasound was diagnosed with mitral regurgitation in all patients. For all surgical procedures, the approach was a vertical midline sternotomy. The mitral valve was approached by left atriotomy in 40 patients (63.5\%) and by transseptal way in 23 patients. All patients had undergone mitral valve repair associated or not with either aortic valve repair in 9 patients (14.2\%), aortic valve replacement in 3 patients (4.8\%), or one tricuspid valve repair in 31 patients (49\%). The average duration of intubation was 6 hours [2 - 52]. The average length of stay in intensive care was 2 days. Postoperative complications have been observed. Surgery was performed in 10 patients with 3 mitral valve replacements, 2 aortic valve replacements, a
\end{abstract}


double mitral and an aortic valve replacement associated with a tricuspid repair and in 4 cases a perfection of their mitral repair. Early and late surgical mortality was zero. The average follow-up time for our patients was 9 months [1 - 26]. During their follow-up, the evolution was favorable in $89 \%$ of patients who no longer had any functional symptoms.

\section{Keywords}

Mitral Valve Repair, Acute Rheumatic Fever, Senegal

\section{Introduction}

In Africa, acute rheumatic fever is endemic. Cardiac involvement is one of the most common complications in the form of valvular heart disease representing all damages to the heart valves [1]. In Senegal, rheumatic heart disease represents the second nosological group of cardiovascular pathology in a hospital setting immediately after high blood pressure [2]. The mitral valve is the most frequently affected [3]. Damage to the mitral valve can result in mitral stenosis, mitral insufficiency or a combination of bothleading to mitral disease [4]. Conservative valve surgery, among others, retains precise indications and has significant advantages especially in children. Valve repair techniques have seen major advances in the last few decades [1]. They require a perfect knowledge of valve damage mechanism.

\section{Objectives}

The main objective was to assess the results of mitral repair in children in Senegal. The specific objective was to clarify the indications for mitral repair surgery and assess the results in terms of morbidity and mortality.

\section{Materials and Methods}

We report a retrospective and analytical monocentric study, in the thoracic and cardiovascular surgery service of FANN National University Hospital Center in Dakar. It covers a period of 30 months or 2 and a half years. All patients who underwent mitral valve repair, aged less than 18 and whose records were complete, were included in the study.

\section{Procedure}

The cannulation was bicaval in all cases. Moderate hypothermia was performed in $94 \%$ of cases (59 patients) with an average temperature of $34^{\circ} \mathrm{C}$. We performed cold blood cardioplegia in 32 patients (50.8\%); Del Nido cardioplegia in $46 \%$ (29 patients) and crystalloid cardioplegia in 2 patients (3\%). Cardioplegia was retrograde in $79 \%$ of cases and anterograde in $21 \%$. The aortic clamping time was $105 \mathrm{~min}$ in average [63 - 164 minutes]. The average duration of cardiopulmonary bypass was 138 minutes [87 - 322 minutes]. 


\section{Results}

The study included 63 patients who underwent mitral valve repair surgery over a period of two and a half years. It includes 39 girls and 24 boys, a sex ratio of 0.62 . The average age at the time of the intervention was 12 years old [5]-[17]. The functional symptomatology was dominated by the dyspnea found in all patients. Only one patient (1.6\%) had NYHA stage 1 dyspnea; 23 patients (36.5\%) had stage 2 dyspnea; 35 patients (55.6\%) stage 3 and 4 patients or (6.3\%) dyspnea stage 4 . Thirty-two patients or $51 \%$ had a history of recurrent angina, 29 patients or $46 \%$ had polyarthralgia and 39 patients or $62 \%$ had at least one episode of cardiac decompensation. The physical examination showed a murmur of mitral valve insufficiency in all patients (Table 1). On the chest X-ray, 54 patients (86\%) had cardiomegaly. Signs of pulmonary hypertension were found in 60 patients (95\%). A complete arrhythmia by atrial fibrillation was found in 13 patients (21\%). Atrioventricular block was found in 2 patients (3\%). Cardiac ultrasound was diagnosed with mitral regurgitation in all patients with a breakdown by mitral insufficiency grade as follows: Grade 1:1 patient (1.6\%); Grade 2:3 patients (4.7\%); Grade 3:20 patients (31.7\%); Grade 4:39 patients (62\%). Mitral valve prolapse was present in 57 patients (90\%); restriction of the posterior valve in 58 patients (92\%). The fusion of commissures was found in 6 patients $(9.5 \%)$. The subvalvular apparatus was affected in 54 patients $(86 \%)$. The mitral ring was dilated in 53 patients (84\%). In 50 of our patients there was a tricuspid insufficiency (79\%) and in 26 patients (41\%) an aortic insufficiency (Table 2).

For all surgical procedures, the approach was a vertical midline sternotomy. The mitral valve was approached by left atriotomy in 40 patients $(63.5 \%)$ and by transseptal way in 23 patients. The mitral valve lesions found were of jet lesion type on the posterior valve (20.6\%), restriction of the posterior valve $(84 \%)$, pseudo prolapse of the anterior valve (92\%), commissural fusion (6.3\%), commissural leaks $(32 \%)$, extension of chordae $(21 \%)$, retraction of chordae $(27 \%)$,

Table 1. Baseline clinical characteristics of the patients.

\begin{tabular}{ccc}
\hline PARAMETERS & NUMBER & PERCENTAGE (\%) \\
\hline NYHA CLASS 1 & 1 & 1.6 \\
NYHA CLASS 2 & 23 & 36.5 \\
NYHA CLASS 3 & 35 & 55.6 \\
NYHA CLASS 4 & 4 & 6.3 \\
PALPITATIONS & 33 & 52 \\
PRECORDIALGIA & 23 & 36 \\
MITRAL INSUFFICIENCY MURMUR & 63 & 100 \\
APEXIAN DIASTOLIC BEARING & 40 & 63.5 \\
HARZER SIGN & 9 & 14 \\
SIGN OF VASCULAR ERETISM & 7 & 11 \\
HEART FAILURE & 7 & 11 \\
\hline
\end{tabular}


Table 2. Summary table of the preoperative echocardiographic data.

\begin{tabular}{cccc}
\hline & Mean & Minimum & Maximum \\
\hline LVSD (mm) & 55.9 & 49 & 80 \\
LVDD (mm) & 35.3 & 27 & 52 \\
LVEF (\%) & 65.2 & 42 & 80 \\
TAPSE (mm) & 21 & 11 & 34 \\
LAD (mm) & 44.9 & 27 & 75 \\
VC (mm) & 5.6 & 8.1 & 2.8 \\
ERO (mm $\left.{ }^{2}\right)$ & 43 & 13 & 69 \\
RV $\left(\mathrm{mm}^{3}\right)$ & 50 & 18 & 109 \\
\hline
\end{tabular}

LVSD: Left Ventricule Systolic Diameter; LVDD: Left Ventricule Diastolic Diameter; LVEF: Left Ventricular Ejection Fraction; TAPSE: Tricuspid Annular Plane Systolic Excursion; LAD: Left Atrial Diameter; VC: Vena Contracta; ERO: Effective Regurgitant Orifice; RV: Regurgitant Volume.

annular dilatation (84\%), presence of indentations (16\%), with calcifications and sometimes the presence of vegetation. All patients had undergone mitral valve repair, whether or not associated with either aortic valve repair in 9 patients (14.2\%), aortic valve replacement in 3 patients (4.8\%), tricuspid valve repair in 31 patients (49\%) with a DeVega plasty type in 9 patients (14.2\%), an annuloplasty with autologous, heterologous or Edwards' ring in 19 patients (30.15\%). In 30 patients $(47.6 \%)$ the mitral repair consisted of an enlargement of the posterior valve by heterologous pericardium while in only 4 patients $(6.3 \%)$ the enlargement plasty involved the anterior valve. Chordae transfer was performed in 24 patients (38\%) and PTFE neochordae were implanted in 10 patients (15.9\%). Closure of indentations was done in 16 patients (25.3\%). A mitral ring was placed in 34 patients (54\%) with 11 Roux Homemade, 7 pericardial rings (heterologous pericardium) and 16 Carpentier rings. Other gestures such as prolapsed leaflet plication (4.8\%), section of secondary chordaes (8\%), closing of slits (8\%), anterior commissural plasty (11\%) and papilary muscles sliding plasty were also made. After the cardiopulmonary bypass breakdown, a transesophageal ultrasound was performed to assess the result of the repair. Moderate to mild mitral leakage was seen in 7 patients (11\%). The average duration of intubation was 6 hours $[2-52 \mathrm{H}]$. The average length of stay in intensive care unit was 2 days. Postoperative complications have been observed. They consisted of multiple organ failure in 5 patients (7.9\%). Hemodynamic instability was found in 10 patients (16\%). Arrhythmias were seen in 20 patients $(31.7 \%)$. Four patients $(6.3 \%)$ had atrioventricular block disorders in 3 patients (4.7\%) and branch block in one patient (1.6\%). Infectious complications were noted in 9 patients $(14.3 \%)$ including one case of infectious endocarditis (1.6\%). Respiratory complications were found in 9 patients (14.3\%). Hemorrhagic complications were noted in 10 patients $(16 \%)$ including tamponade in one patient (1.6\%). Surgery was performed in 10 patients with 3 mitral valve replacements, 2 aortic valve replacements, a double mitral and aortic valve replacement associated with a tricuspid 
plasty and in 4 cases a perfection of their mitral plasties. Early and late surgery mortality was zero. The average follow-up time for our patients was 9 months [ 1 - 26]. Post-surgery follow-up concerned only 59 patients since 4 patients had benefited from a replacement of the mitral valve before their discharge. During their follow-up, the evolution was favorable in $89 \%$ of patients who no longer had any functional symptoms. We do not have any notion of recurrent dyspnea. On ultrasound control, the average systolic ejection fraction was 56\% [31\% 74\%] and 19 patients (32\%) had mitral leak ranging from minimal to moderate in 17 patients (28.8\%), and a massive leak in two patients (3.3\%). During their follow-up, they showed a reappearance of stage 4 dyspnea. Two patients had undergone another surgery for replacement of the mitral valve.

\section{Discussion}

In the series, we note a female predominance with a sex ratio of 0.62 as in the literature [5] [6] [7]. The relatively young average age of the patients is related to the prevalence of rheumatic disease in developing countries but also to the youth of African population. Most of the series from underdeveloped countries report a similar age, namely a more frequent attack of subjects of school age [3] [5] [7]. Among the 20 million rheumatic heart diseases listed worldwide and the 500,000 deaths attributed to them, $95 \%$ occurs in underdeveloped or developing countries. Sub-Saharan Africa is believed to be responsible for half of the cases on the continent [8]. Thus, valve disease occurs in a relatively young population, unlike the series in developed countries where the elderly predominates. In our study population, the etiology is infectious. Our region is a rheumatic endemic area. Before their admission, the majority of patients (55.6\%) had stage 3 dyspnea as in most studies [5] [9] and $62 \%$ of them had at least one episode of cardiac decompensation. This confirms a fairly advanced course of the disease before diagnosis and/or management. Cardiac ultrasound is the examination we chose to confirm the diagnosis of mitral valve disease and establish a therapeutic strategy. It assesses the severity of the lesions, the mechanism of leak, the valve surfaces, the state of the subvalvular apparatus, the impact on the heart chambers, pulmonary pressures and cardiac function. In rheumatic disorders, the valve morphology is generally typical with a pseudoprolapse of the anterior leaflet in its different segments A1, A2, or A3; annular dilation, restriction of the posterior valve and shortening and fusion of the valvular apparatus are frequently found as a mechanism for mitral regurgitation [8]. Involvement of the subvalvular apparatus is manifested by fusion of chordae, shortening and/or thickening of the pillars and chordaes [10]. We found these typical lesions in our patients, at various stages. All had a rheumatic valve morphology. The dilation of the left cavities is frequent $(84 \%)$. We have a high frequency of pulmonary arterial hypertension. The mitral valve is exposed by left atriotomy in $63.5 \%$ of cases and by transseptal way in $36.5 \%$ in cases where the left atrium was not very dilated. After careful examinations of the lesions, we found in most cases a mitral insufficiency by prolapse of the A2 segment of the large valve (92\%) and a restriction of 
the posterior valve. These proportions are often found in rheumatic disorders [11] [12] [13]. This prolapse of the anterior valve is due to a rupture or elongation of chordae. During the repair of the mitral valve, we proceed to an enlargement of the posterior valve in the majority of cases (47\%) according to the technique of Carpentier [4]. Surgical techniques also included the insertion of a mitral ring (54\%) which makes it possible to reduce the size of the native ring and thus participates in the prevention of secondary dilation [10], the transfer of chordae (38\%), the insertion of neochorade (15.2\%), the closure of indentations $(25.3 \%)$. These corrections are completed by a commissurotomy in the event of a commissure fusion. Similar proportions are found in the literature [14]. We report a higher frequency of aortic valve repair $(14.2 \%)$ than aortic valve replacement (4.8\%). There has been renewed interest in aortic plastic techniques for some time. This is linked to the fact that the morbidity linked to valvular prostheses is not negligible [15] and that the aortic plasty avoids the disadvantages of the implantation of prosthetic material in the young population (risk of early degeneration of bioprostheses, complications of anticoagulants oral, endocarditis) whose expectation and quality of life must be considered in the choice of therapeutic modalities [16]. Tricuspid valve surgery is performed as soon as tricuspid insufficiency is rated as average. Tricuspid insufficiencies have been demonstrated as a factor of poor prognosis with high morbidity and mortality in patients operated for valvulopathy of the left heart [17]. Valvular involvement is more functional than organic. The purpose of the repair is to preserve the right ventricular function. Among the 31 patients who underwent tricuspid plasty, the majority of plasties were performed using the DeVega technique (9 patients) and Carpentier (9 patients). The plasty technique according to De Vega has advantages related to the absence of foreign material, therefore a very low economic cost and a shortened operating time. Conversely, Carpentier ring annuloplasty requires the installation of a ring. The results of the two techniques are satisfactory and can be superposed in the short and medium term, however the plasty with Carpentier ring presents better long-term results [17]. Post-surgery complications are hemodynamic, pulmonary, infectious. There are also rhythm and conduction disturbances. We observe hemodynamic complications in $23.8 \%$ of cases. Patients with ventricular dysfunction received inotropic and tonicardiac support. In the event of a pulmonary arterial hypertension crisis, we combine milrinone continuously with a relay with sildenafil. The evolution is generally favorable. Conduction disorders after cardiac surgery are quite frequent with an incidence between $1.2 \%$ and $7 \%$ depending on the series [9] [16] [18]. In this series, they are $6.3 \%$ and are transient. Respiratory complications including pneumonitis and pleural effusions had a rate of $14.3 \%$ supported by the results of the series of Bakkali [9] and Talwar [18] however other series such as that of Gos [19] and Duran [16] found a much lower rate. The 8 repeat operations concern the mitral valve with 4 replacements of the mitral valve by a mechanical valve and 4 corrections of the mitral plasty. Surgery mortality in our series is zero as in most series where this mortality is low [5] [9] [16] [18] [20]. However, 
there are differences in terms of medium-term results; this is strongly linked to the experience of the surgical team in mitral repair [15]. The best immediate results are reported by Gos [19] in 200 patients. That said, the results obtained in our series are very promising.

\section{Conflicts of Interest}

The authors declare no conflicts of interest regarding the publication of this paper.

\section{References}

[1] Reul, R.M. and Cohn, L.H. (1997) Mitral Valve Reconstruction for Mitral Insufficiency. Progress in Cardiovascular Diseases, 39, 567-599.

https://doi.org/10.1016/S0033-0620(97)80015-1

[2] Diagne, P.A. (2012) Thèse de médecine No. 182. Faculté de médecine de Dakar.

[3] Essop, M.R. and Nkomo, V.T. (2005) Rheumatic and Nonrheumatic Valvular Heart Disease Epidemiology, Management, and Prevention in Africa. Circulation, 112, 3584-3591. https://doi.org/10.1161/CIRCULATIONAHA.105.539775

[4] Carpentier, A. (1983) Cardiac Valve Surgery: The "French Correction". Journal of Thoracic and Cardiovascular Surgery, 86, 323-337. https://doi.org/10.1016/S0022-5223(19)39144-5

[5] Ciss, A.G., Diarra, O., Dieng, P.A., et al. (2009) La plastie mitrale sur valve rhumatismale chez l'enfant au Sénégal: 100 observations. Medecine tropicale, 69, 278-280.

[6] Samiei, N., Hakimi, M.R., Peighambari, M.M., Alizadeh-Ghavidel, A. and Hossein, S. (2014) Surgical Outcomes of Heart Valves Replacement: A Study of Tertiary Specialied Cardiac Center. ARYA Atherosclerosis, 10, 233-237.

[7] Yayehd, K., Kouleke, D., Tchamdja, T., Tcherou, T., Pessinaba, S. and Damorou, F. (2012) Valvulopathies rhumatismales à Lomé: Aspects épidémiologiques et prise en charge. Journal de la Recherche Scientifique de I Université de Lomé, 14, 51-58.

[8] Roudaut, R., Dijos, M., Arsac, F., Reant, P. and Lafitte, S. (2011) Pathologie valvulaire: 50 ans de progrès. AMC pratique, 200, 21-23.

https://doi.org/10.1016/S1261-694X(11)70255-3

[9] Bakkali, A., Jaabari, I., Belkhadir, A. and Laaroussi, M. (2017) Les résultats de la plastie mitrale dans la pathologie rhumatismale. Journal de chirurgie thoracique et cardiovasculaire, 21.

[10] Aubert, S., Praschker, B.L., Coignard, E. and Gandjbakhch, I. (2008) La plastie mitrale dans tous ses états. MT cardio, 4, 291-296.

[11] Chauvaud, S., Fuzellier, J.F., Berrebi, A., Deloche, A., Fabiani, J.N. and Carpentier, A. (2001) Long-Term (29 Years) Results of Reconstructive Surgery in Rheumatic Mitral Valve Insufficiency. Circulation, 104, I12-I15. https://doi.org/10.1161/hc37t1.094707

[12] Konate, I. (2010) These de médecine: Valvulopathies mitrale réussite et échec: A propos de 40 cas.

[13] Yau, T.M., El-Ghoneimi, Y.A.F., Armstrong, S., et al. (2000) Mitral Valve Repair and Replacement for Rheumatic Disease. The Journal of Thoracic and Cardiovascular Surgery, 119, 53-61. https://doi.org/10.1016/S0022-5223(00)70217-0

[14] Kalangos, A. (2012) The Rheumatic Mitral Valve and Repair Techniques in Child- 
ren. Seminars in Thoracic and Cardiovascular Surgery, 15, 80-87. https://doi.org/10.1053/j.pcsu.2012.01.013

[15] Alec, V. and Garbarz, E. (2011) Bernard Iung Les cardiopathies acquises de l'enfant dans les pays en voie de développement. Bulletin de Pacadémie nationale de médecine, 195, 315-326. https://doi.org/10.1016/S0001-4079(19)32090-4

[16] Duran, C.M., Gometza, B. and de Vol, E.B. (1991) Valve repair in rheumatic mitral disease. Circulation, 84, 125-132.

[17] Charfeddine, S., Hammami, R., Triki, F., et al. (2017) La plastie tricuspide: Annuloplastie de Carpentier versus technique de De VEGA. The Pan African Medical Journal, 27, 119. https://doi.org/10.11604/pamj.2017.27.119.8868

[18] Talwar, S., Raman Rajesh, M., Subramanian, A., et al. (2005) Mitral Valve Repair in Children with Rheumatic Heart Disease. The Journal of Thoracic and Cardiovascular Surgery, 129, 875-879. https://doi.org/10.1016/j.jtcvs.2004.11.006

[19] Gos, A., Christenson, J.T., Beghetti, M., et al. (2008) Mitral Valve Repair for Rheumatic Valve Disease in Children: Midterm Results and Impact of the Use of a Biodegradable Mitral Ring. The Annals of Thoracic Surgery, 86, 161-169. https://doi.org/10.1016/j.athoracsur.2008.03.005

[20] Antunes, M.J., Magalhaes, M.P., Colsen, P.R. and Kinsley, R.H. (1987) Valvuloplasty for Rheumatic Mitral Valve Disease. A Surgical Challenge. The Journal of Thoracic and Cardiovascular Surgery, 94, 44-56.

https://doi.org/10.1016/S0022-5223(19)36316-0 